\title{
Сорбция ионов меди фрильтрующим материалом АС
}

\author{
Линников О.Д., Родина И.В., Тютюнник А.П., \\ Еселевич Д.А., Соколова Л.Л. \\ ФГБУН Институт химии твёрдого тела УрО РАН, Екатеринбург \\ Поступила в редакцию 11.04.2016 г.
}

\begin{abstract}
На модельном растворе изучена сорбция ионов двухвалентной меди минеральным фильтрующим материалом АС. Показано, что сорбционные свойства АС обусловлены одновременным действием двух факторов. Первый из них связан с повышением $\mathrm{pH}$ очищаемого раствора при вводе в него $\mathrm{AC}$, что приводит к осаждению из раствора гидроксида меди. Второй - заключается в способности АC удалять из раствора ионы меди по механизму мономолекулярной адсорбции, описываемой уравнением Ленгмюра. Установлено, что с повышением $\mathrm{pH}$ раствора от 4 до 6.7 адсорбция ионов меди на поверхности $\mathrm{AC}$ возрастает (диапазоны $\mathrm{pH}<4$ и $\mathrm{pH}>6.7$ не были исследованы).

Ключевые слова: сорбция, очистка воды, ионы меди(II), адсорбция, уравнение Ленгмюра.
\end{abstract}

\section{Sorption of ions $\mathrm{Cu}^{2+}$ by filtrate material $\mathrm{AC}$}

\author{
Linnikov O.D., Rodina I.V., Tjutjunnik A.P., Eselevich D.A., Sokolova L.L. \\ Institute of Solid State Chemistry, Ural Branch of the RAS, Ekaterinburg
}

The sorption of ions $\mathrm{Cu}^{2+}$ by mineral filtrate material $\mathrm{AC}$ was investigated using imitating solution. The imitating solution contained $\mathrm{CuSO}_{4}$ and $400 \mathrm{mg} / 1 \mathrm{Na}_{2} \mathrm{SO}_{4}$. It was shown that sorption properties of $\mathrm{AC}$ are result of two factors. The first factor is an increasing of $\mathrm{pH}$ of solution after introduction into it AC. This leads to precipitation of $\mathrm{Cu}(\mathrm{OH})_{2}$ from the solution. The second one is facility of $\mathrm{AC}$ to remove ions $\mathrm{Cu}^{2+}$ from solution under mechanism of monomolecular adsorption described by the Langmuir equation. It was established that adsorption of ions $\mathrm{Cu}^{2+}$ onto surface of $\mathrm{AC}$ increases as $\mathrm{pH}$ of solution increases from 4 to 6.7 (the ranges of $\mathrm{pH}<4$ and $\mathrm{pH}>6.7$ were not investigated).

The adsorption capacity of $\mathrm{AC}$ for ions $\mathrm{Cu}^{2+}$ in dimension of $\mathrm{mg} / \mathrm{l}$ is near of analogous ones for other mineral sorbents. But in dimension of $\mathrm{mg} / \mathrm{m}^{2}$ the adsorption capacity of $\mathrm{AC}$ is about in two order of value lower in compare with the adsorption capacity of other sorbents. Taking into account that base of $\mathrm{AC}$ is $\mathrm{SiO}_{2}$ one can conclude that silica is not effective as an adsorbent for ions $\mathrm{Cu}^{2+}$. Nevertheless, at very low concentration of $\mathrm{Cu}^{2+}$ in a solution, when there is no precipitation of $\mathrm{Cu}(\mathrm{OH})_{2}, \mathrm{AC}$ can remove ions $\mathrm{Cu}^{2+}$ from polluted solutions because of their adsorption on the surface of AC.

Keywords: sorption, purification of water, ions $\mathrm{Cu}^{2+}$, adsorption, the Langmuir equation.

\section{Введение}

Очистка природных и сточных вод от ионов меди является важной экологической задачей, обусловленной, прежде всего, достаточно высокой токсичностью последних. Так, ПДК по ионам меди для питьевой воды и водоёмов хозяйственно-

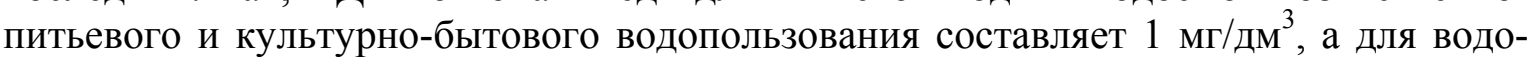
ёмов, имеющих рыбохозяйственное значение - 0.001 мг/дм ${ }^{3}$ [1]. Видно, что наиболее жёсткие требования предъявляются к водам водоёмов рыбохозяйственного назначения, к которым относится большинство рек и озёр России. При этом обычные спосо- 
бы очистки стоков, основанные на подщелачивании загрязнённой воды с помощью известкового молока до $\mathrm{pH}=8-9$ и последующем осаждении из неё гидроксидов цветных и тяжёлых металлов, не позволяют достичь требуемой глубины очистки сточных вод от ионов меди перед сбросом их в данные водоёмы. Так, практика показывает, что остаточная концентрация меди в очищенной воде при $\mathrm{pH}=8-9$ обычно находится на уровне 0.1-0.2 мг/дм ${ }^{3}$ [1], что неплохо согласуется с соответствующими теоретическими расчётами по растворимости гидроксида меди в водных растворах [2].

Между тем, данная задача, возможно, может быть решена с помощью сорбционных методов очистки, в частности, с использованием неорганических сорбентов. Следует отметить, что в этом направлении было проведено достаточно большое количество исследований [2-8], однако интерес к изучению сорбционных свойств новых соединений и ряда природных минералов не ослабевает.

Целью настоящей работы является исследование сорбционных свойств промышленного минерального фильтрующего материала АC, выпускаемого АО «АЛСИС» (г. Екатеринбург), по отношению к ионам двухвалентной меди. Данный материал рекомендуется производителем для осветления воды и очистки её от железа, стронция, алюминия, фенола, фтора и нефтепродуктов. Его сорбционные свойства по отношению к ионам меди и другим катионам цветных и тяжёлых металлов изучены ещё недостаточно [3, 4].

\section{Эксперимент}

Фильтрующий минеральный материал (сорбент) АС представляет собой порошок слабо розового цвета. Для исследования была взята фракция АС размером 0.315-0.7 мм. Эксперименты проводили на модельном водном растворе, имитирующем природные и сточные воды, который готовили путём растворения в дистиллированной воде сульфатов натрия и меди $\left(\mathrm{Na}_{2} \mathrm{SO}_{4}\right.$ и $\left.\mathrm{CuSO}_{4}\right)$. Концентрация сульфата натрия в модельном растворе была равна 400 мг/дм³ , а ионов меди менялась в разных экспериментах, но не превышала 15 мг/дм³ ${ }^{3}$ Все опыты проводили при комнатной температуре $\left(25 \pm 2^{\circ} \mathrm{C}\right)$ и непрерывном перемешивании магнитной мешалкой модельного раствора, в который добавлялся сорбент. Затем через 30 минут выдержки сорбента в перемешиваемом мешалкой растворе из него отбирали пробу на анализ. Фильтрация отобранных проб раствора производилась под вакуумом, так как обычным способом отделить сорбент от раствора было трудно (процесс фильтрования занимал очень много времени). При этом предварительные анализы показали, что при фильтрации растворов с низкой концентрацией меди происходит сорбция части ионов меди на используемом бумажном фильтре синяя лента, в результате которой концентрация меди в отфильтрованном растворе уменьшается. Это искажает результаты анализа. Поэтому, чтобы снизить ошибку определения меди (при фильтрации отобранной пробы через бумажный фильтр), первая порция фильтрата, объёмом около $100 \mathrm{~cm}^{3}$, отбрасывалась и на анализ бралась оставшаяся часть пробы раствора (отфильтрованная через этот же фильтр), концентрацию меди(II) в которой определяли фотоколориметрическим методом с диэтилдитиокарбоматом натрия на фотоколориметре КФК-2 [9].

Часть экспериментов была выполнена при разных значениях $\mathrm{pH}$ раствора. При этом коррекцию $\mathrm{pH}$ раствора до требуемого значения производили только после ввода сорбента в модельный раствор, а последующее поддержание в ходе опыта $\mathrm{pH}$ раствора на заданном уровне осуществляли с помощью рН-метра АНИОН 4100 (погрешность определения \pm 0.05 ед. $\mathrm{pH}$ ) и $0.1 \mathrm{~N}$ растворов серной кислоты и $\mathrm{NaOH}$. 
Отметим, что в этих и других подобных экспериментах электроды рН-метра были постоянно погружены в модельный раствор с сорбентом в течение всего опыта. Рентгенофазовый анализ полученных порошков выполнялся на дифрактометре ДРОН-6 в излучении $\mathrm{Ka}-\mathrm{Cu}$. Удельная поверхность порошка $\mathrm{AC}\left(106.38 \mathrm{~m}^{2} / г\right)$ и объём пор $\left(6.29 \cdot 10^{-4} \mathrm{~cm}^{3} / \Gamma\right)$ были определены методом БЭТ по адсорбции азота на установке Gemini VII 2390 V1.03 (USA).

Химический анализ фильтрующего материала АC был выполнен по стандартными методикам с переводом твёрдой фазы в раствор и с последующим его анализом атомно-адсорбционным методом. Относительная погрешность определений составила $10 \%$.

\section{Обсуждение результатов}

Результаты химического и рентгенофазового анализа сорбента АС приведёны ниже в табл. 1 и 2.

Таблица 1. Результаты рентгенофазового анализа (РФА) сорбента АС

\begin{tabular}{|c|c|}
\hline Обнаруженная фаза & Содержание по данным РФА, масс. \% \\
\hline $\mathrm{SiO}_{2}$ (кварц) & 41.71 \\
\hline $\mathrm{SiO}_{2}$ (тридимит) & 22.70 \\
\hline $\mathrm{SiO}_{2}$ (кристобалит) & 14.32 \\
\hline $\mathrm{MgAlSi}_{4} \mathrm{O}_{10} \mathrm{OH} \times 4 \mathrm{H}_{2} \mathrm{O}$ (полыгорскит) & 7.47 \\
\hline $\mathrm{Fe}_{2} \mathrm{O}_{3}$ (гематит) & 12.87 \\
\hline
\end{tabular}

Таблица 2. Результаты химического анализа сорбента АC

\begin{tabular}{|c|c|c|c|c|c|c|}
\hline Определяемый компонент & $\mathrm{Al}$ & $\mathrm{Ca}$ & $\mathrm{Fe}$ & $\mathrm{Mg}$ & $\mathrm{S}$ & $\mathrm{Si}$ \\
\hline $\begin{array}{c}\text { Содержание определяемого } \\
\text { компонента, масс. \% }\end{array}$ & 1.5 & 0.7 & 2.2 & 0.9 & 0.012 & 40 \\
\hline
\end{tabular}

Из данных табл. 1 и 2 видно, что сорбент АС состоит в основном из соединений кремния (кварц, тридимит, кристобалит, полыгорскит) и гематита. Кроме того, в AC содержится также, по-видимому, небольшое количество кальцийсодержащих минералов (табл. 2), которые не удалось определить рентгенофазовым анализом.

При выдержке сорбента в дистиллированной воде наблюдалось повышение её $\mathrm{pH}$, обусловленное, видимо, частичным растворением в ней полыгорскита и соединений кальция (рис. 1 и 2). Химический анализ дистиллированной воды после выдержки в нёй АC показал наличие в растворе ионов кальция (15 мг/дм $\left.{ }^{3}\right)$, магния $\left(2.4\right.$ мг/дм $\left.{ }^{3}\right)$ и кремния (46.5 мг/дм в пересчёте на $\left.\mathrm{SiO}_{2}\right)$.

Как видно из рис. 1, изменение рН дистиллированной воды при выдержке в ней фильтрующего материала АС носило немонотонный характер. Вначале $\mathrm{pH}$ раствора довольно быстро возрастал, а затем происходило его небольшое снижение и через 30-40 мин выход на плато. Причиной этого может быть, например, растворение полыгорскита в дистиллированной воде и последующий гидролиз ионов алюминия в растворе, который протекает довольно медленно [10]. Этим же, возможно, объясняется плохая фильтруемость суспензии АС после выдержки сорбента в водном растворе (образовавшиеся мельчайшие частицы гидроксида алюминия быстро забивают поры фильтровальной бумаги, что приводит к резкому снижению скорости фильтрования). Обращает на себя внимание факт несоответствия размера частиц порошка сорбента (фракция размером 0.315-0.7 мм) его удельной поверхности (106.38 м²/г). Так, если плотность материала АС согласно [4] составляет примерно 
2300 кг $/ \mathrm{M}^{3}$, то при шарообразной форме частиц и их диаметре 0.315-0.7 мм удельная поверхность сорбента должна лежать в пределах 3.7-8.38 м²/г. Наблюдаемое расхождение можно объяснить, если предположить, что частицы порошка АС представляют собой агломераты из более мелких частичек. При плотности материала АС 2300 кг $/ \mathrm{m}^{3}$ и его удельной поверхности $106.38 \mathrm{~m}^{2} / \Gamma$ размер этих частичек в агломератах должен составлять около 25 нм.

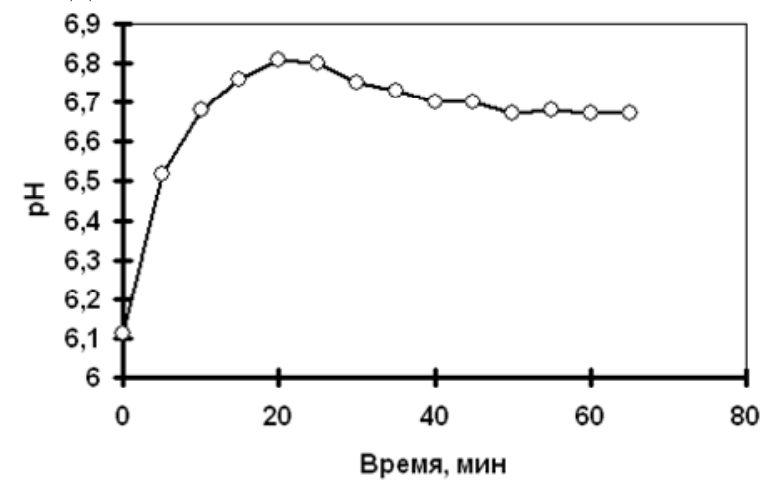

Рис. 1. Кинетика изменения $\mathrm{pH}$ дистиллированной воды при выдержке в ней сорбента АС при постоянном перемешивании суспензии магнитной мешалкой

(концентрация сорбента в растворе

$$
\mathrm{C}_{\mathrm{s}}=2 \Gamma / \text { дм }^{3} \text { ) }
$$

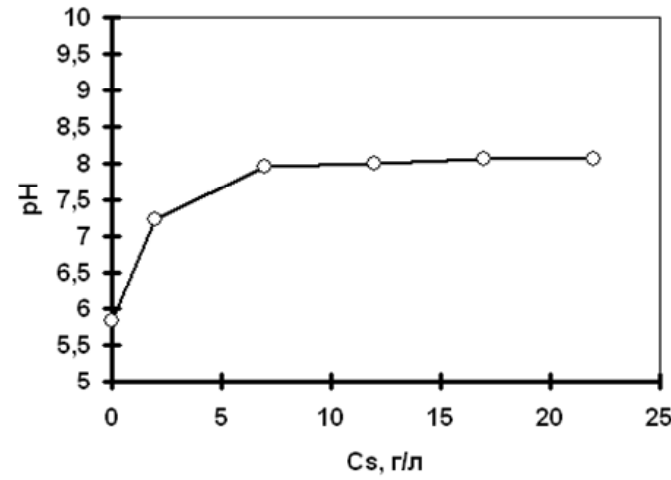

Рис. 2. Влияние концентрации АС в растворе на рН последнего (время выдержки сорбента в растворе $\tau=30$ мин, раствор - дистиллированная вода)

Очевидно, что повышение $\mathrm{pH}$ раствора, вызванное введением в него АC, приведёт к тому, что нежелательные примеси в виде катионов тяжёлых металлов, содержащиеся в загрязнённом растворе, выпадут в осадок в форме соответствующих гидроксидов. Таким образом, можно предположить, что эффект очистки загрязнённых растворов от данного типа примесей при использовании минерального материала АС будет обусловлен в основном увеличением $\mathrm{pH}$ раствора. Этот эффект хорошо демонстрируют рис. 3 и 4. Так, рис. 3 показывает, что с ростом содержания АС в модельном растворе концентрация ионов меди в нём резко снижается. При этом одновременно возрастает $\mathrm{pH}$ очищаемого раствора. Для наглядности на рис. 3 рядом с экспериментальными точками приведены соответствующие им значения $\mathrm{pH}$ модельного раствора.

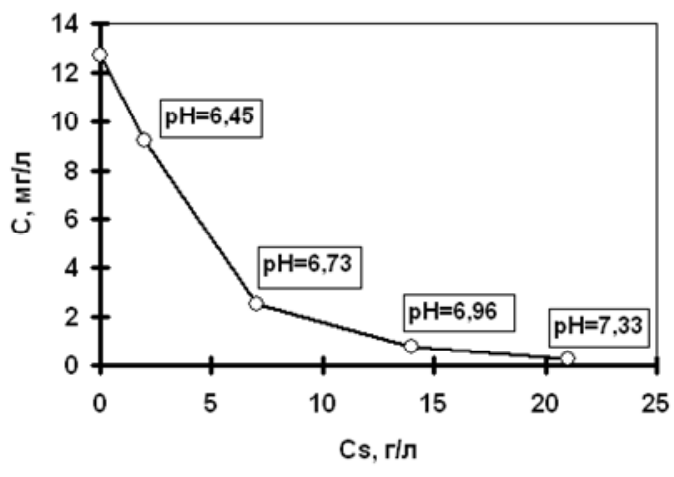

Рис. 3. Влияние концентрации $\mathrm{AC}$ на остаточное содержание меди (C) в модельном растворе (начальная концентрация ионов меди в растворе

$$
\mathrm{C}_{\text {in }}=12.72 \mathrm{мг} / \text { дм }^{3}, \tau=30 \text { мин) }
$$

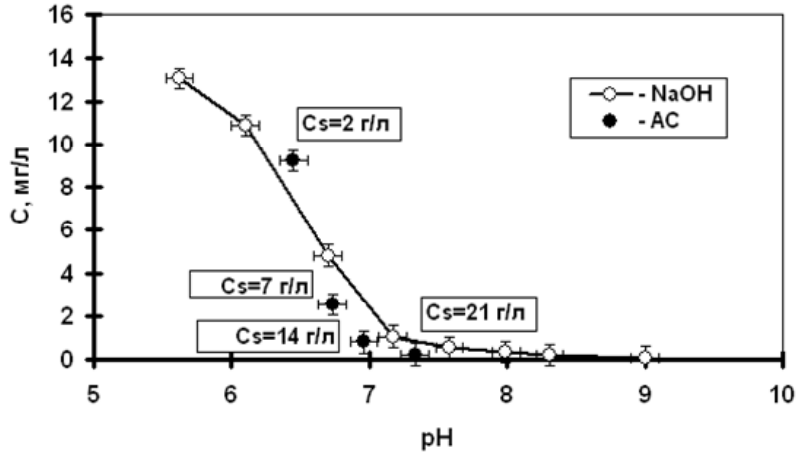

Рис. 4. Влияние $\mathrm{pH}$ и концентрации сорбента АС в модельном растворе на остаточное содержание в нём ионов меди $\left(\mathrm{C}_{\mathrm{in}}=12.72 \mathrm{мг} /\right.$ дм $\left.^{3}, \tau=30 \mathrm{мин}\right)$. 
На рис. 4 экспериментальные результаты, представленные на рис. 3, совмещены с данными, полученными при подщелачивании модельного раствора (без введённого в него фильтрующего материала $\mathrm{AC}$ ) раствором едкого натра. В последнем случае в модельный раствор для повышения его $\mathrm{pH}$, медленно добавляли раствор $\mathrm{NaOH}$, и после 30 минутной выдержки из него отбирали пробу на анализ. Для АС на рис. 4 рядом с каждой опытной точкой показана концентрация сорбента в растворе, взятая с рис. 3 .

Как видно, экспериментальные точки для обеих серий опытов, независимо от того каким образом достигалось данное значение $\mathrm{pH}$ раствора (путём введения в модельный раствор щёлочи или за счёт добавления в него сорбента АC), легли практически на одну кривую (имеющиеся расхождения находятся в пределах экспериментальной ошибки). Это подтверждает, что удаление ионов меди из очищаемого раствора при добавлении в него материала АС происходит в основном за счёт повышения его рН (что приводит к выпадению в осадок гидроксида меди). Влияние же адсорбции на процесс очистки раствора от ионов меди, по-видимому, незначительно. Однако, что интересно, если пересчитать полученные опытные данные по классическому уравнению Ленгмюра для мономолекулярной адсорбции:

$$
A=A_{\infty} \frac{K \cdot C}{1+K \cdot C} .
$$

где $A$ - величина адсорбции, мг/г или мг/м ${ }^{2} ; A_{\infty}$ - ёмкость адсорбционного монослоя

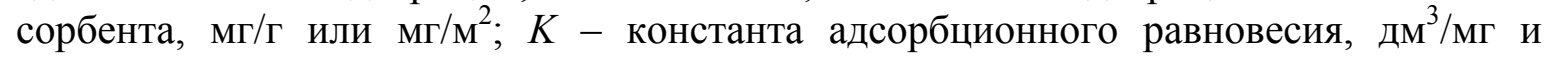
построить график в координатах его линейной формы, то, как видно из рис. 5, расчётные точки неплохо аппроксимируются прямой (коэффициент корреляции 0.96), подтверждающей справедливость уравнения (1). Отсюда, если не принимать во внимание результаты, представленные на рис. 2-4, можно сделать ошибочный вывод об удалении ионов меди из очищаемого раствора за счёт их физической адсорбции на поверхности фильтрующего материала АС.

Для того, чтобы определить действительный (а не мнимый) вклад физической адсорбции в процесс удаления ионов меди из раствора при использовании фильтрующего материала АC, были проведены эксперименты, в которых $\mathrm{pH}$ модельного раствора поддерживали постоянным на протяжении всего опыта за счёт его корректировки растворами серной кислоты и едкого натра. Такая постановка экспериментов позволила исключить влияние фактора увеличения $\mathrm{pH}$ раствора (при введении в него AC) на осаждение меди в виде гидроксида. Кроме того, в этих опытах начальная концентрация меди в модельном растворе была задана ниже концентрации, соответствующей растворимости гидроксида меди при данном $\mathrm{pH}$. В частности, начальная концентрация меди в растворе задавалась исходя из экспериментальных данных по осаждению меди щёлочью, представленных на рис. 4.

Так, например, при проведении сорбции при $\mathrm{pH}=6$ начальная концентрация ионов меди в модельном растворе была выбрана равной 6.36 мг/дм ${ }^{3}$, а в экспериментах при $\mathrm{pH}=6.7-3.816$ мг/дм ${ }^{3}$, что существенно меньше концентраций, соответствующих растворимости гидроксида меди при данных $\mathrm{pH}$ (примерно 11 и 5 мг/дм ${ }^{3}$ соответственно, см. рис. 4) в условиях наших опытов. Результаты некоторых из этих экспериментов представлены на рис. 6 в координатах линейной формы уравнения (1). Как видно, экспериментальные точки хорошо ложатся на прямую. Это свидетельствует о том, что фильтрующий материал АС способен удалять ионы меди из загрязнённого раствора не только за счёт его подщелачивания, но также и путём физической адсорбции последних на своей поверхности.

Линников и др. / Сорбционные и хроматографические процессы. 2017. Т. 17. № 1 


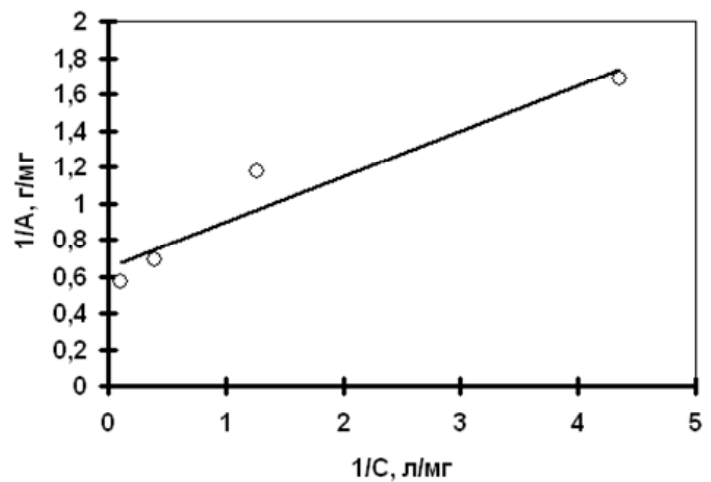

Рис. 5. Экспериментальные данные по сорбции ионов меди из модельного раствора при введении в него сорбента AC в координатах преобразованного уравнения (1)

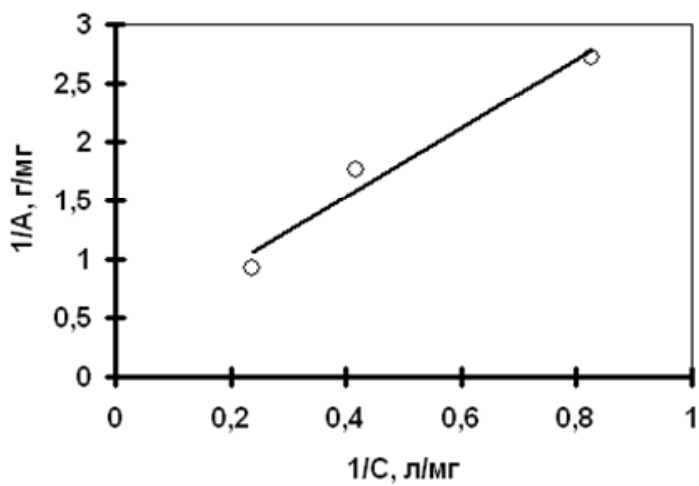

Рис. 6. Экспериментальные данные по сорбции ионов меди из модельного раствора при $\mathrm{pH}=6$ сорбентом $\mathrm{AC}$

в координатах линейной формы уравнения (1)

Полученные данные позволили рассчитать параметры уравнения Ленгмюра (табл. 3). Отметим, что при $\mathrm{pH}<4$ адсорбция ионов меди фильтрующим материалом в данной работе не изучалась.

Таблица 3. Зависимость параметров уравнения (1) от рН раствора, в котором протекает процесс сорбции ионов меди ( $\mathrm{R}_{\mathrm{c}}$ - коэффициент корреляции)

\begin{tabular}{|c|c|c|c|c|}
\hline $\mathrm{pH}$ & $A_{\infty}, \mathrm{M \Gamma} / \Gamma$ & $A_{\infty}, \mathrm{M} \Gamma / \mathrm{M}^{2}$ & $K, \mathrm{дm}^{3} / \mathrm{M \Gamma}$ & $\mathrm{R}_{\mathrm{c}}$ \\
\hline 4 & 0.1323 & 0.0012 & 0.2844 & 0.99 \\
\hline 5 & 1.4921 & 0.0140 & 0.0555 & 0.79 \\
\hline 6 & 2.7181 & 0.0256 & 0.1263 & 0.98 \\
\hline 6.7 & 7.3964 & 0.0695 & 0.2058 & 0.94 \\
\hline
\end{tabular}

Из данных табл. 3 видно, что ёмкость адсорбционного монослоя материала $\mathrm{AC} \mathrm{c} \mathrm{повышением} \mathrm{pH}$ раствора резко возрастает. Одновременно с этим наблюдается рост константы адсорбционного равновесия (если не принимать во внимание "выпадающее" значение константы при $\mathrm{pH}=4$, которому мы пока не можем дать объяснения). При $\mathrm{pH}>6.7$ получить достоверные результаты нам не удалось из-за большой экспериментальной ошибки определения концентрации ионов меди в растворе.

Сорбционное извлечение катионов двухвалентной меди из водных растворов сорбентом АС ранее изучалось в работе [3]. Было установлено, что эффективность сорбции меди сорбентом АС повышается при увеличении $\mathrm{pH}$ раствора от 2 до 6-8 (что согласуется с нашими результатами), а затем начинает снижаться. Сорбционная ёмкость АС по отношению к ионам меди оказалась равной 2.8 мг/г, что также близко к нашим данным. Однако, к сожалению, в [3] нет никаких сведений о механизме удаления меди сорбентом АС и не указано значение $\mathrm{pH}$ раствора, для которого определена сорбционная ёмкость. Остаётся только предполагать, что это диапазон $\mathrm{pH}=6$ 8, в котором, согласно [3], сорбция имеет максимальное значение.

В работе [4] были также изучены сорбционные свойства фильтрующего материала АC и, кроме того, сорбента МС (последний тоже является минеральным фильтрующим материалом и также выпускается АО «Алсис» (г. Екатеринбург)). Основу обоих сорбентов составляет кремнезём. Однако в МС, согласно данным [4], также присутствует большое количество магния. Установлено, что эффективность сорбции ионов меди обоими сорбентами возрастает с ростом $\mathrm{pH}$ раствора от 1 до 3 и в дальнейшем уже не меняется. Сорбция хорошо описывается уравнением Ленгмю- 
ра. Для частиц сорбентов диаметром 0.7 мм (что близко к размеру частиц исследованного нами порошка АC) сорбционная ёмкость по ионам меди для АС составила $3.4 \mathrm{мг} / г$, а МС - 3.8 мг/г. Расчёт по зависимостям, представленным на рис. 1 работы [4] даёт, однако, другие значения. Для сорбента АС получается 10.29 мг/г, а для МС - 11.22 мг/г. Причина такого расхождения между представленными в работе [4] экспериментальными данными не совсем ясна. Если ориентироваться на рис. 1 этой работы, то для констант адсорбционного равновесия можно получить следующие зна-

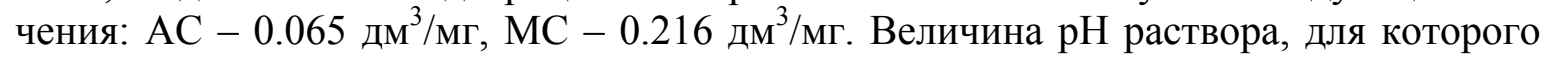
была определена сорбционная ёмкость в работе [4] тоже не указана. Следует добавить, что мы практически не нашли работ, в которых авторы учитывали бы влияние фактора повышения $\mathrm{pH}$ очищаемого раствора при вводе в него сорбента на удаление из раствора катионов тяжёлых металлов путём их осаждения в виде соответствующих гидроксидов.

Представляет интерес далее сравнить полученные экспериментальные результаты с аналогичными данными для других сорбентов, которые имеют близкий химический и минералогический состав. Так, сорбция ионов меди природными сорбентами мергель и опока, относящимися к цеолитсодержащему сырью, была изучена в [5]. Мергель содержит в своём составе карбонаты (кальцит, доломит) и глинистые частицы. Опока - кремнезём с мезопористой структурой, состоящий из $\mathrm{SiO}_{2}(75-$ $80 \%), \mathrm{Al}_{2} \mathrm{O}_{3}(18-23 \%)$ и оксидов кальция, железа, магния [5]. Судя по фазовому составу, оба сорбента при их введении в водный раствор должны повышать его рН. Однако влияние этого эффекта на удаление меди из очищаемого раствора в работе [5] не изучалось. При описании полученных результатов уравнением Ленгмюра найдены следующие значения его параметров: мергель - $A_{\infty}=2.33$ ммоль $/ \Gamma=148$ мг $/ \Gamma$ и $K=26.87 \quad$ дм ${ }^{3} /$ ммоль $=0.423 \quad$ дм $^{3} /$ мг; опока - $A_{\infty}=1.15 \quad$ ммоль $/ \Gamma=73 \quad$ мг $/ \Gamma \quad$ и

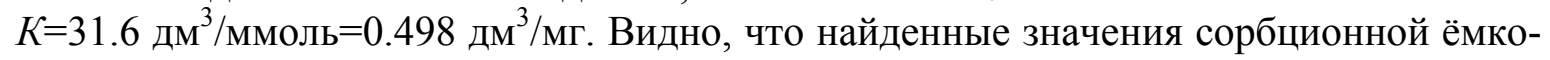
сти достаточно велики и обусловлены, скорее всего, эффектом подщелачивания раствора при вводе в него сорбентов, а согласование экспериментальных данных с уравнением Ленгмюра, как и в нашем случае (рис. 5), является случайным.

Сорбция ионов меди натриевой формой бентонита с удельной поверхностью $28.82 \mathrm{~m}^{2} / \Gamma$ изучена в работе [6]. Бентонит представляет собой неорганический ионообменный материал, основу которого составляет гидроалюмосиликат. Сорбционные эксперименты проводились с использованием растворов нитрата меди(II). Показано, что с ростом рН раствора эффективность удаления из него ионов меди бентонитом возрастает и при $\mathrm{pH}=7-9$ выходит на плато. Исследования при $\mathrm{pH}>9$ не проводились [6]. Полученные экспериментальные данные лучше всего описывались изотермой сорбции Ленгмюра с параметрами: $A_{\infty}=26.1643$ мг $/ \Gamma=0.9079$ мг $/ \mathrm{м}^{2}$ и $K=0.2664 \mathrm{gm}^{3} / \mathrm{Mг}$. Величина $\mathrm{pH}$, для которого определены параметры изотермы сорбции, в работе [6] не указана.

Сорбция ионов меди сепиолитовой (S) и монтмориллонитовой (M) глинами изучена в [7]. По химическому составу эти глины состояли в основном из кремнезёма (53.47 и $57.80 \% \mathrm{SiO}_{2}$ соответственно) с небольшой примесью соединений других металлов (Al, $\mathrm{Fe}, \mathrm{Ca}, \mathrm{Mg}, \mathrm{K}, \mathrm{Na}, \mathrm{Ti})$, и имели следующую удельную поверхность: сепиолитовая глина $-82.35 \mathrm{~m}^{2} / \Gamma$, монтмориллонитовая глина - $73.92 \mathrm{~m}^{2} / \Gamma$ [7]. Для исследования использовался раствор хлорида меди(II). Было установлено, что лучше всего сорбция меди описывается изотермой Ленгмюра с параметрами: $\mathrm{S}$ $A_{\infty}=19.01 \mathrm{мг} / \Gamma=0.231 \mathrm{мг} / \mathrm{M}^{2}, K=0.069 \mathrm{дм}^{3} / \mathrm{M \Gamma} ; \mathrm{M}-A_{\infty}=18.69 \mathrm{мг} / \Gamma=0.253 \mathrm{мг} / \mathrm{m}^{2}, K=0.041$ дм $^{3}$ мг [7]. Значение $\mathrm{pH}$ раствора, при котором были определены параметры уравнения Ленгмюра, к сожалению, не указано.

Линников и др. / Сорбционные и хроматографические процессы. 2017. Т. 17. № 1 
По данным, приведённым в работах [7 и 8], ёмкость монослоя различных минеральных сорбентов по отношению к ионам меди лежит в диапазоне от 1.01 до $55.56 \mathrm{M \Gamma} / \Gamma$.

\section{Заключение}

Таким образом, проведённые исследования показали, что минеральный фильтрующий материал $\mathrm{AC}$ способен очищать загрязнённые растворы от ионов двухвалентной меди. Причём сорбционные свойства АС обусловлены одновременным действием двух факторов. Первый из них связан с повышением рН очищаемого раствора при вводе в него сорбента, что приводит к осаждению из раствора гидроксида меди. Второй - заключается в способности АС удалять из раствора ионы меди по механизму мономолекулярной адсорбции, описываемой уравнением Ленгмюра. Эксперименты показали, что с повышением рН раствора от 4 до 6.7 адсорбция ионов меди на поверхности АС возрастает (диапазоны $\mathrm{pH}<4$ и $\mathrm{pH}>6.7$ не были исследованы).

Адсорбционная ёмкость монослоя фильтрующего материала АC по отношению к ионам меди, выраженная в размерности мг/г, близка по своему значению к аналогичным величинам для других минеральных сорбентов. Однако при пересчёте ёмкости монослоя АС в размерность мг/м² получаются значения, которые на порядок ниже адсорбционной ёмкости монослоя других сорбентов. Так как основу фильтрующего материала АС составляет чистый кремнезём, то можно сделать вывод, что он не эффективен как адсорбент по отношению к ионам двухвалентной меди. Тем не менее, даже при очень низкой концентрации последних в растворе, когда подщелачивание раствора при вводе в него АС не будет приводить к осаждению из него гидроксида меди, сорбент АС может эффективно очищать загрязнённые растворы от ионов меди за счёт своей большой удельной поверхности.

Работа выполнена при поддержке проекта Президиума УрО РАН №15-11-3-10.

\section{Список литература}

1. Виноградов С.С., Кудрявцев В.Н. // Водоснабжение и канализащия. 2010. № 5-6. С. 113-118.

2. Марков В.Ф., Формазюк Н.И., Маскаева Л.Н., Макурин Ю.Н., Степановских Е.И. // Альтернативная энергетика и экология. 2007. T. 47. № 3. С. 144-149.

3. Хурамшина И.З., Никифоров А.Ф., Липунов И.Н., Первова И.Г. // Сорбиионные и хроматографические проиессы. 2014. Т. 14. № 2. C. 338-344.

4. Фоминых И.М. Автореферат канд. диссертации. Екатеринбург. 2006. 26 с.

5. Лозинская Е.Ф., Митракова Т.Н., Жиляева Н.А. // Учёные записки: электронный журнал Курского государственного универcumema. 2013. T. 2. № 3(27).

6. Zhi-rong L., Shao-qi Z. // Desalination and Water Treatment. 2012. Vol. 44. pp. 223-228.

7. Coruh S., Geyikci F. // Desalination and Water Treatment. 2012. Vol. 45. pp. 351-360.

8. Aydin H., Yerlikaya C., Uzan S. // Desalination and Water Treatment. 2012. Vol. 44. pp. 296-305.

9. Новиков Ю.В., Ласточкин К.О., Болдина 3.Н. Методы исследования качества воды водоёмов. М. Медицина. 1990. 400 с.

10. Линников О.Д., Родина И.В., Аксёнов В.Н., Никулин В.А., Пецура С.С. // Водоснабжение и санитарная техника. 2009. № 12. C. $38-41$. 


\section{References}

1. Vinogradov S.S., Kudryavtsev V.N., Water supply and sewerage, 2010, No 5-6, pp. 113118 (in Russian).

2. Markov V.F., Formazuk N.I., Maskaeva L.N., Makurin U.N., Stepanovskih E.I., International Scientific Journal for Alternative Energy and Ecology, 2007, Vol. 47, No 3, pp. 144-149 (in Russian).

3. Huramshina I.Z., Nikiforov A.F., Lipunov I.N., Pervova I.G., Sorbtsionnye i khromatograficheskie protsessy, 2014, Vol. 14, No 2, pp. 338-344 (in Russian).

4. Fominyh I.M. Abstract cand. diss. Ekaterinburg, 2006, 26 p (in Russian).

5. Lozinskaya E.F., Mitrakova T.N., Zhilyaeva N.A. Scientific notes: electronic journal of

Линников Олег Дмитриевич - д.х.н., зав. лаб. Института химии твёрдого тела УрО РАН, Екатеринбург

Родина Ирина Васильевна - инженер 1-й категории Института химии твёрдого тела УрО РАН, Екатеринбург

Тютюнник Александр Петрович - к.ф-м.н., зав. лаб. Института химии твёрдого тела УрО РАН, Екатеринбург

Еселевич Даниил Александрович - научный сотрудник Института химии твёрдого тела УрО РАН, г. Екатеринбург

Соколова Лена Лябибовна - инженер 1-й категории Института химии твёрдого тела УрО РАН, Екатеринбург
Kursk's State University, 2013, Vol. 2, No 3(27) (in Russian).

6. Zhi-rong L., Shao-qi Z., Desalination and Water Treatment, 2012, Vol. 44, pp. 223-228.

7. Coruh S., Geyikci F., Desalination and $\mathrm{Wa}-$ ter Treatment, 2012, Vol. 45, pp. 351-360.

8. Aydin H., Yerlikaya C., Uzan S., Desalination and Water Treatment, 2012, Vol. 44, pp. 296-305.

9. Novikov U.V., Lastochkin K.O., Boldina Z.N. Metody issledovania kachestva vody vodoemov. M., Meditsina, 1990, 400 p (in Russian).

10. Linnikov O.D., Rodina I.V., Aksenov V.N., Nikulin V.A., Petsura S.S., Water supply and sanitary engineering, 2009, No 12, pp. 3841 (in Russian).

Linnikov Oleg D. - Head of Laboratory, PhD, Dr. Sci. (Physical Chemistry), Institute of Solid State Chemistry, Ural Branch of the Russian Academy of Sciences, Ekaterinburg, E-mail: linnikov@mail.ru

Rodina Irina V.- researcher, Institute of Solid State Chemistry, Ural Branch of the Russian Academy of Sciences, Ekaterinburg

Tjutjunnik Aleksandr P. - Head of Laboratory, $\mathrm{PhD}$, Institute of Solid State Chemistry, Ural Branch of the Russian Academy of Sciences, Ekaterinburg

Eselevich Daniil A. - research associate, Institute of Solid State Chemistry, Ural Branch of the Russian Academy of Sciences, Ekaterinburg

Sokolova Lena L.- researcher, Institute of Solid State Chemistry, Ural Branch of the Russian Academy of Sciences, Ekaterinburg 